Research Article

\title{
Study on Floor Mechanical Failure Characteristics and Stress Evolution in Double Predriven Recovery Rooms
}

\author{
Guorui Feng, ${ }^{1,2}$ Songyu Li $\mathbb{D}^{1,2}$ Pengfei Wang $\mathbb{D}^{1,2}$ Jun Guo, ${ }^{1,2}$ Ruipeng Qian, ${ }^{1,2}$ \\ Qiang Sun, ${ }^{1,2}$ Chenliang Hao, ${ }^{1,2}$ Xiaoze Wen, ${ }^{1,2}$ and Jianan Liu ${ }^{1,2}$ \\ ${ }^{1}$ College of Mining Technology, Taiyuan University of Technology, Taiyuan 030024, China \\ ${ }^{2}$ Shanxi Province Research Center of Green Mining Engineering Technology, Taiyuan 030024, China \\ Correspondence should be addressed to Pengfei Wang; 18801448768@163.com
}

Received 18 November 2019; Revised 10 March 2020; Accepted 16 March 2020; Published 21 April 2020

Academic Editor: Ali Ramazani

Copyright (C) 2020 Guorui Feng et al. This is an open access article distributed under the Creative Commons Attribution License, which permits unrestricted use, distribution, and reproduction in any medium, provided the original work is properly cited.

\begin{abstract}
This paper takes the double predriven recovery rooms (DPRR) of 31109 panel of a coal mine in Inner Mongolia as a case study. DPRRs are used to withdraw mining equipment, which play a significant role in safe and efficient production in the final longwall mining stage. Theoretical analysis and numerical simulation were carried out to study the reasonable size of the front abutment pillar between DPRR (inter-DPRR pillar) and the damage depth of the DPRR floor. The results show that (1) the stress distribution of the fender (the remnant longwall panel) can be approximately divided into three stages with the advance of the working face: stress redistribution (the first) stage, stress superimposed growth (the second) stage, and stress transfer (the third) stage. (2) According to stress distribution and the corresponding failure mode of the fender, the calculation model of the slippage damage of the DPRR floor is rectified, and the damage range of the floor is rezoned to make it more suitable for the damage depth of the room. (3) The zone of influence of the front abutment pressure is $40-50 \mathrm{~m}$, and the stress around the DPRR increases significantly in the final mining stage. When the size of the inter-DPRR pillar is greater than $15 \mathrm{~m}$, the effect of increasing the coal pillar size on lowering the peak stress of the main predriven recovery room is limited. (4) Floor heave tends to increase at first and then decrease with depth and reaches the maximum in the depth of $5 \mathrm{~m}$ in the final mining stage, indicating that $5 \mathrm{~m}$ is the starting point for the initial depth of the floor heave. (5) The theoretical calculation shows that the reasonable size of the inter-DPRR pillar is $20 \mathrm{~m}$, and the critical width of the fender is $18.48 \mathrm{~m}$, which can guide the secondary support to prevent dynamic disasters. Floor grouting and constructing concrete floor are effective and economic ways to control the floor heave.
\end{abstract}

\section{Introduction}

Double predriven recovery rooms (DPRRs) play a significant role in safe and efficient production in the longwall mining final stage [1-3]. DPRR are roadways excavated in advance next to the stopping line coal pillar and are extensively used in China [4]. DPRRs are used to withdraw the mining equipment, which is the main method to speed up recovery of the longwall [5-7], and the withdrawal system of DPRR is shown in Figure 1.

As the working face continues to advance, caving of roof strata begins when they overhang for a significant distance. The overburden pressure, previously undertaken by the coal mass, is transferred to surrounding abutments [8-10]. Liu et al. [11] carried out physical simulations to study the sudden closure of hydraulic supports when the working face crossed the abandoned roadway and investigated the distribution of front abutment pressure and failure characteristics of the surrounding rock. Yin et al. [12] used the catastrophe theory to explain the instability mechanism of coal pillar between the working face and the abandoned roadway and used the elastic plate theory to study the stress state and breakage position of the main roof after the pillar failure. Liu et al. [13] conducted a 2D simulation experiment and mechanical analysis to reveal the loading mechanism. The result shows that when the working face advances close to roadways, the main roof breaks ahead of the working face and leads to instability of higher strata. These two changes 


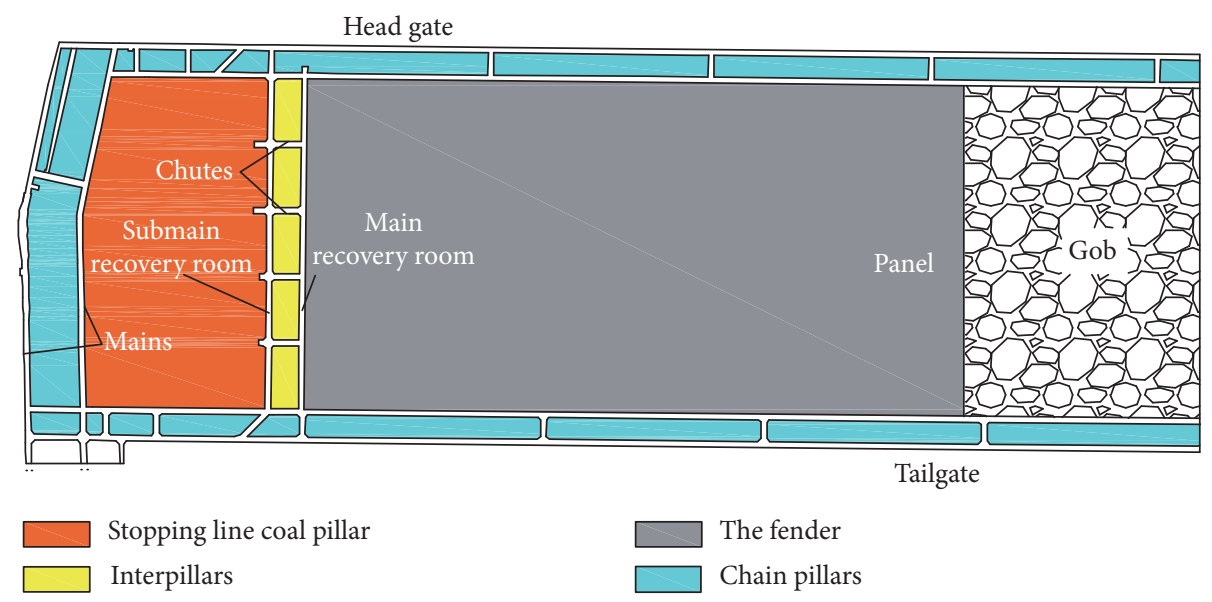

FIgURE 1: Plan view of the withdrawal system with DPRR.

induce a sharp increase of the load on supports and lead to an accident. Wang et al. [14] pointed out that brief pause of mining at a proper position according to the law of periodic weighting is a means to avoid the influence of ground pressure upon completion of the panel, which can change the starting location and decrease the length of continuous pressure by halting or reducing mining velocity. Wang et al. [15] conducted two case studies to evaluate the surrounding rock deformation and stress evolution in predriven longwall recovery rooms. The result shows that when the main roof breaks above the coal pillar, the surrounding rock deformations of the main recovery room and the coal pillar stress increase sharply. The last weighting is the key factor affecting the stability of the main recovery room and the coal pillar; the main roof breaks at unfavorable positions, which is the main cause of the support crushing accidents. Xie et al. [16] established a structural model of the main roof during crossing abandoned roadway, gained the critical working resistance of support under the long key block, and studied the stress distribution and failure characteristic of the surrounding rock using numerical modelling. The above analysis pointed out that the stress distribution and deformation of the pillar are a function of failure in the coal and the strata around the coal. That is, the stress distribution and deformation of pillars are dependent on the strength properties of the strata surrounding the coal.

The stress around DPRR is susceptible to the front abutment pressure, which would interact and gradually overlap with surrounding stress of DPRR in the final mining stage [17]. In addition, with the reduction of the fender, front abutment pressure of the working face may transmit from the fender (the remnant longwall panel) to the interpillar, which makes the DPRR in an ever-changing and dynamic nonuniform stress field environment [18]. Many studies indicate that the front abutment pillar between DPRR plays a key role in the mining equipment withdrawal system upon completion of a panel [19-23]. Gu et al. [24] proposed a loading transfer mechanism between the fender and interDPRR pillar based on theoretical analysis. Feng et al. present results for using an irregular yield pillar for gate road stability in a split-level panel layout at a coal mine. Li et al. [25] used theoretical analysis and numerical simulation to determine the front pressure distribution when the longwall face is $70,50,30,20,10$, and $5 \mathrm{~m}$ from the abandoned roadways. Wang et al. [26] conducted a numerical method to systematically simulate the laws of stress evolution, failure, and roadway deformation of inter-DPRR pillar with the different widths under the secondary mining influence. Different sizes of inter-DPRR pillar correspond with different distribution characteristics of front abutment pressure, and the deformation law of the DPRR floor is also complicated. Inter-DPRR pillar design is an important and convenient engineering control measure for lowering the risks of roof caving and pillar failure in the final mining stage.

When the DPRR floor is weak or the size of the interDPRR pillar is unreasonable, dynamic pressure around the working face is high in the final mining stage and asymmetric destruction of the DPRR floor is developed. Several researchers proposed that deformation of the DPRR floor depends on several factors including lithology, width of the inter-DPRR pillar, cover depth, periodic weighting interval, and mining stress [8, 10, 11, 24]. Jia et al. [27] analyzed the stress environment, dramatic asymmetrical floor heave, and failure characteristics of the coal roadway in the fully mechanized caving face. Zhang et al. [28] adopted the slip line field theory of plastic mechanics for deriving the formula of maximum breakage depth of the coal seam floor and analyzed the relationship between the maximum breakage depth of the coal seam floor and its contributing factors. Chen et al. [9] analyzed the form, process, and characteristics of retained gob-side entry and concluded that shear slip failure is the main floor failure mode. Severe floor heave will reduce the cross-sectional area of DPRR, which significantly impedes the recovery efficiency even fails to recover the mining equipment. It is necessary to calculate the reasonable size of the pillar and clarify the stress distribution law and the damage mechanism of the DPRR floor in the final mining stage.

However, theoretical analysis and numerical simulation research on the stress distribution of longwall panel when it approaches the DPRR have not seen reported yet. When the 
longwall panel approaches the DPRR, the front abutment pressure distribution has different characteristics. Stress distribution of DPRR also changed correspondingly. It is important to set up the advanced and secondary support according to pressure distributions to prevent the floor heave and dynamic disasters [25]. Therefore, this paper presents stress distribution and corresponding failure mode of the pillar and calculation model for maximum failure depth of pillar floor with longwall panel mining. Numerical modelling was used to study the distribution of front abutment pressure with different sizes of inter-DPRR pillars and the fender.

\section{Site Description}

The case study site is 31109 working panel in Lijiahao Coal Mine, Shenhua Group, which is located in Baotou City, Inner Mongolia, China. This coal mine was built in 2006 with an estimated service life of 71 years. The designed production capacity is 6 million tons per year. The sizes of DPRR are both $5.4 \mathrm{~m}$ (wide) $\times 4 \mathrm{~m}$ (height). 31109 working panel is $300 \mathrm{~m}$ wide and $4154.75 \mathrm{~m}$ long with a fully mechanized top coal caving method.

The basic tectonic formation at Lijiahao Mine Field is a monoclinic structure with a southwestern dip direction. The rock stratum has a dip angle of $3^{\circ}$. The geological condition is simple. The cover depth is about $230 \mathrm{~m}$. It currently mines $3-1 \#$ coal seam with an average thickness of about $6.2 \mathrm{~m}$. The coal seam inclination angle is $0 \sim 3^{\circ}$. The immediate roof of the coal seam is mainly sandy mudstone. The main roof consists of fine sandstone, while the floor consists mainly of mudstone. Figure 2 shows the stratigraphy column.

The 31109 working panel is extracted by fully mechanized top coal caving method, and the DPRRs are excavated along the floor. The recovery system is retracted by the main and submain rooms. There are several chutes connecting the rooms and several shunting chambers. The width of the inter-DPRR pillar is $25 \mathrm{~m}$. The plan view of the local panel layout is shown in Figure 3. According to the mining and longwall move experience of the adjacent panels, DPRRs in the final mining stage are prone to problems of roof fall, rib spalling, and floor heave. Among them, floor heave is most prominent, which seriously affects the efficiency of longwall move. The field floor heave situation of DPRR is shown in Figure 4.

\section{Failure Mechanism Analysis of DPRR}

3.1. Stress Distribution of DPRR and Zoning for the Fender. The DPRR can greatly improve the efficiency of longwall move. However, as the withdrawal system consists of the main and submain recovery rooms, the DPRR surrounding rock stress under the influence of front abutment pressure has a sharp increase in the final mining stage compared with the common gate roads. Therefore, DPRRs in the final mining stage are prone to problems of roof fall, rib spalling, and floor heave when the equipment is retracted, which seriously affects the efficiency of longwall move [26]. The reason is that, with the advance of the working face, the fender gradually reduces, and the front abutment pressure is transmitted from the fender to the front inter-DPRR pillar [24]. Therefore, the stresses of the fender and inter-DPRR pillar are superimposed and transferred with the mining, as shown in Figure 5.

The fender stress distribution on the working face can be approximately divided into three stages: when the working face is far away from the DPRR, the front abutment pressure has not affected DPRR surrounding rock. The stress distribution of the fender is in the first stage-stress redistribution stage due to excavation of DPRR; with the advance of the working face, the front abutment pressure is superimposed on the DPRR surrounding rock stress. The fender stress distribution is in the second stage-stress superimposed growth stage; As the bearing capacity of the fender drops with the advance of the working face toward the rooms, the front abutment pressure will gradually transfer from the fender to the inter-DPRR pillar. The stress distribution of the fender enters the third stage-stress transfer stage. Throughout the above three stages, DPRR surrounding rock is in a high stress state and there is a significant increase in floor heave between the second and third stages. Therefore, the proper sizes of the inter-DPRR pillar and reasonable time for installing reinforcement need to be determined according to the stress distribution of DPRR.

In the final mining stage, stress distribution and zoning for the fender is shown in Figure 5. The fender can be divided into four zones: stress-relaxation fractured zone (in red), stress-concentration plastic zone (in blue), stress-concentration elastic zone (in pink), and premining stress elastic zone (in green) that has not been disturbed in the middle of the fender [17]. Figure 6 shows the stress distribution and the corresponding failure mode of the fender in different stages. When the size of the fender is reduced to $S_{1}$, the premining stress elastic zone (in green) disappears in the coal pillar. Front abutment pressure gradually affects the stress distribution around the DPRR, corresponding to the second stage of the fender stress distribution-the stress superimposed growth stage. When the size of the fender is reduced to $S_{2}$, the stress-concentration elastic zone (in pink) disappears in the coal pillar, whose stress value reaches the maximum. And the fender is completely in plastic state, corresponding to the stage between the end of the second and the beginning of the third stage, which is the appropriate time for lowering mining speed to reduce roof pressure. When the size of the fender is reduced to $S_{3}$, the coal pillars have completely lost the bearing capacity. The overburden load is assumed by the inter-DPRR pillars, corresponding to the second stage of the fender stress distribution-stress transfer stage.

At the final mining stage, the ribs of DPRR are subjected to high stress. During the stress superimposed growth stage, front abutment pressure acts on the surrounding rock of DPRR floor, which will inevitably become a position for stress release. When the floor is soft, the stress transmitted from the ribs reaches the breaking strength of the floor, and the DPRRs are inwardly raised, which severely affects the stability of the ribs, resulting in the slowness of longwall move, sometimes even fail to withdraw mining equipment.

This paper draws on the calculation method of foundation damage depth in soil mechanics to calculate and 


\begin{tabular}{|c|c|c|c|c|c|}
\hline $\begin{array}{c}\text { Thickness } \\
\text { (m) }\end{array}$ & Rock strata & Number & Lithology & Lithological discription & FLAC $^{3 \mathrm{D}}$ colorby \\
\hline 4.9 & $\overline{-1}=$ & 9 & Sandy mudstone & Dark gray sandy mudstone with poor sorting & \\
\hline 4 & $\ldots$ & 8 & Siltstone & Grayish-black siltstone & \\
\hline 5.5 & m" n." & 7 & Siltstone & Grayish-black siltstone with not developed bedding & \\
\hline 18.6 & ...... & 6 & Fine sandstone & Gray line sandstone, argillaceous cementation & \\
\hline 6.4 & $\bar{z}=$ & 5 & Sandy mudstone & Dark gray sand mudstone with poor sorting & \\
\hline 6.2 & & 4 & $3-1 \#$ Coal seam & $3-1 \#$ Coal is mainly vitrinite with little bright and dark strip & \\
\hline 12.8 & $\frac{-}{-}--$ & 3 & Mudstone & Black mudstone, high carbon content & \\
\hline 9.2 & $=$ & 2 & Siltstone & Grayish-black siltstone with not developed bedding & \\
\hline 4.9 & 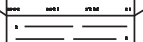 & 1 & Sandy mudstone & Dark gray sandy mudstonr with poor sorting and a few plant fossils & \\
\hline
\end{tabular}

FIgURE 2: The stratigraphy column of 3-1\# at 31109 panel.

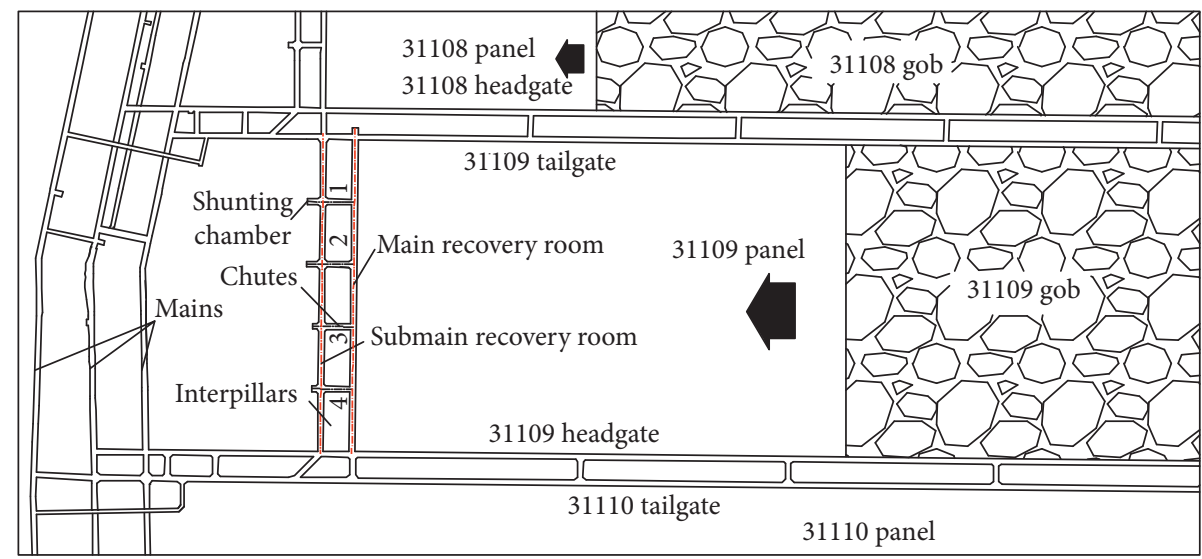

FIgUre 3: Plan view of the local panel layout.

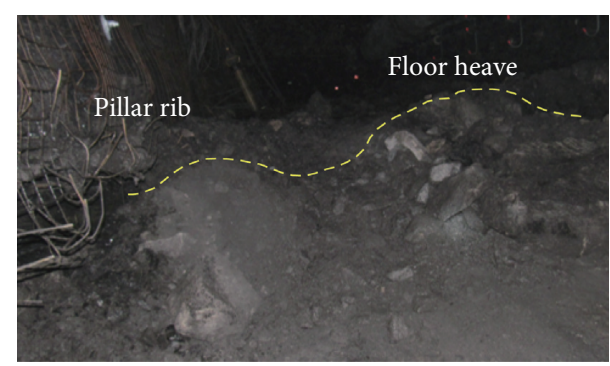

FIgURE 4: Field photo of floor heave and pillar rib.

analyze the failure range of the DPRR floor in the final mining stage. According to the influence of different sizes of inter-DPRR pillars on the failure depth of floor rock, reasonable width of the inter-DPRR pillar against the background of 31109 working face is proposed.

3.2. Establishment of Slip Line Equation. The slip line is obtained by connecting the shear failure surfaces of each point. Through any element, there are two fracture surfaces (the tangential direction of the slip line is the direction of the corresponding point's slip surface) [29]. The angle between the failure surface and the maximum principal stress is $\mp \mu$, respectively. $\alpha$ and $\beta$ are two-group slip lines, and the corresponding direction angles are $\theta-\mu$ and $\theta+\mu$, respectively. Therefore, the differential equations of the two slip lines $(\alpha$ and $\beta$ ) are obtained based on the basic equation of plastic mechanics and the Coulomb-Mohr yield criterion in Figure 7 [30]:

$$
\frac{d_{x}}{d_{y}}=\tan (\theta+n \mu),
$$

where $n$ is the coefficient corresponding to the slip line group; when $n$ is -1 , it indicates the $\alpha$ family slip line, and when $n$ is 1 , it indicates the $\beta$ family slip line; $\theta$ is the angle between the maximum principal stress $\sigma_{1}$ and the $x$-axis, $\mu$ is the angle between the failure surface and the maximum principal stress, and $\varphi$ is the friction angle.

3.3. Model Simplification and Correction. According to the theory of slip line field [31], the range of slippage damage is divided into three zones: I-the active stress zone (the angle between the slip line and the DPRR floor is $\pi / 4+\varphi / 2)$, II-the transition zone, and III-passive stress zone (the angle between the slip line and the DPRR floor is $\pi / 4-\varphi / 2$ ), as shown in Figure 8.

According to the literature [32-36], the stress distribution law of coal pillars and the foundation in soil 


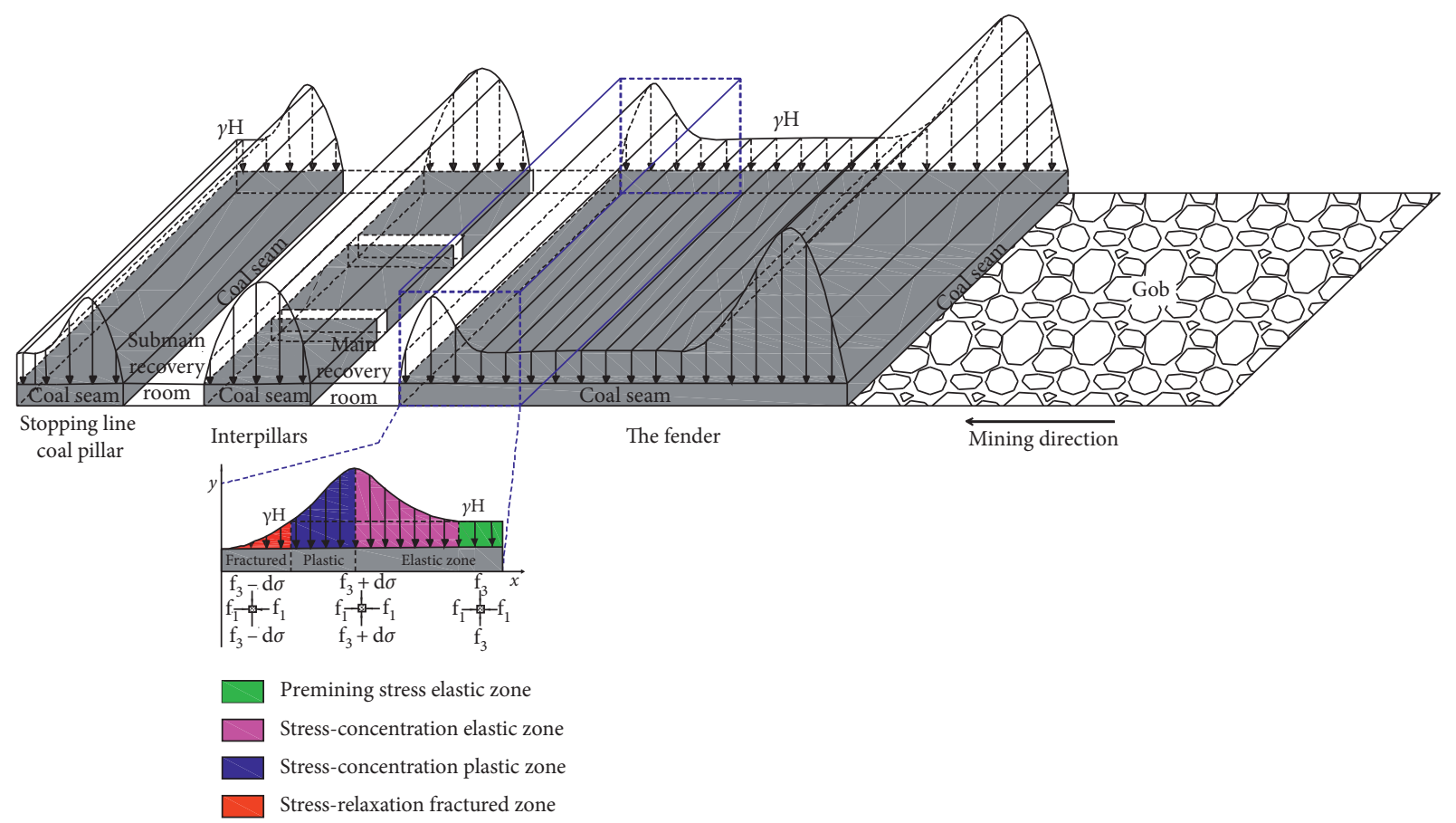

FIGURE 5: Stress distribution of DPRR and zoning for the fender.

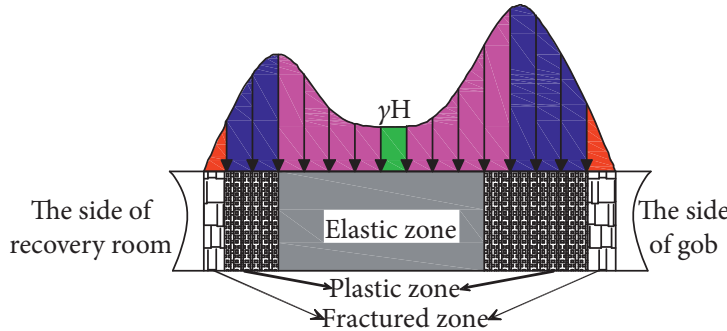

(a)

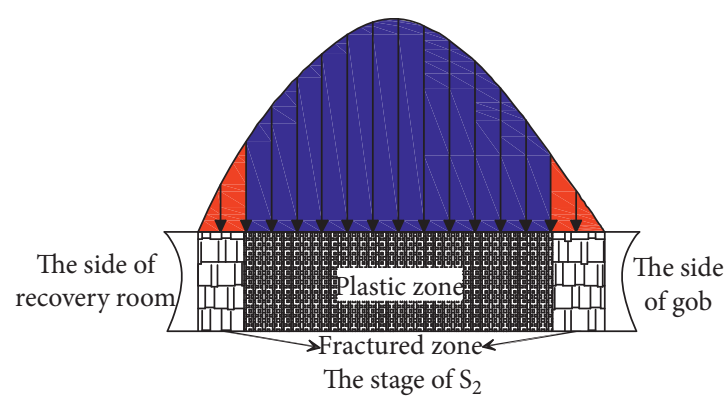

(c)

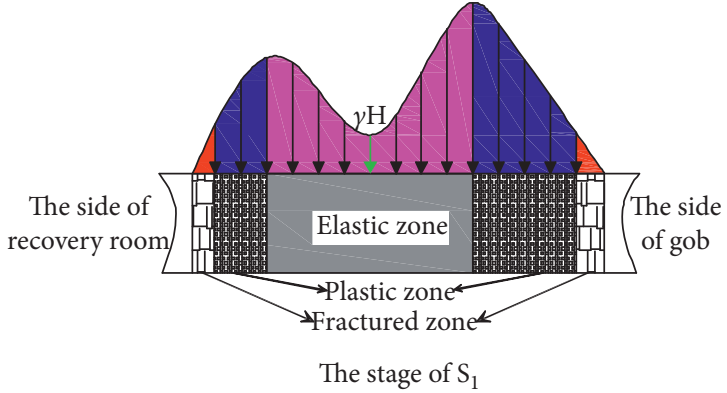

(b)

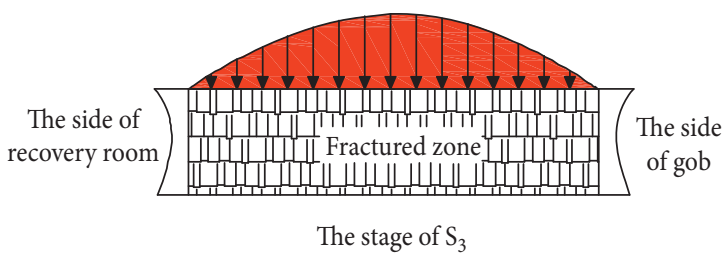

(d)

FIgURE 6: Stress distribution and corresponding failure mode of the fender in different stages.

mechanics is not exactly the same. The foundation is calculated as a whole without stress-relaxation zone. The stress on the coal pillar is nonuniform, and there are stress-relaxation zone and stress-concentration zone in the coal pillars. The stress in the stress-relaxation zone of the coal pillar is not large enough to cause damage in the coal pillar floor, and this part of the coal pillar has undergone plastic deformation, which does not carry much load. Therefore, when calculating the damage range of the coal pillar floor, the calculated width of coal pillars should exclude the stressrelaxation plastic zone. Based on the above analysis combined with the slip line field theory, the slip zone and the slip 


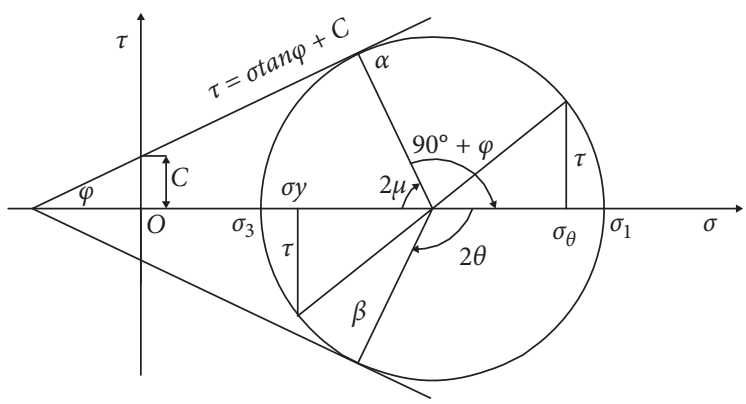

(a)

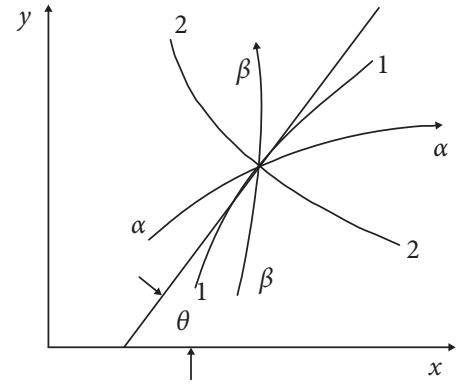

(b)

Figure 7: (a) Coulomb-Mohr yield condition and (b) slip line coordinate system.

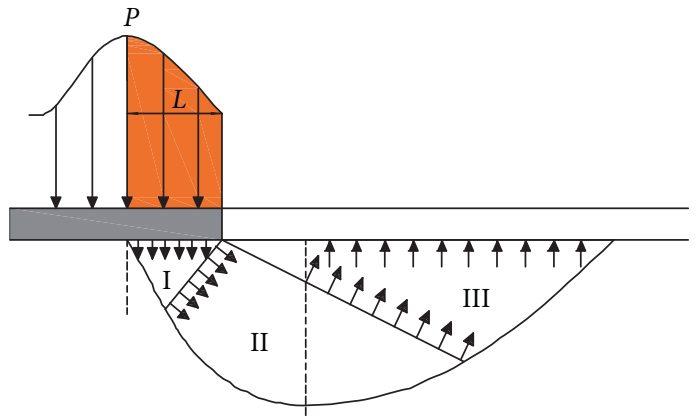

(a)

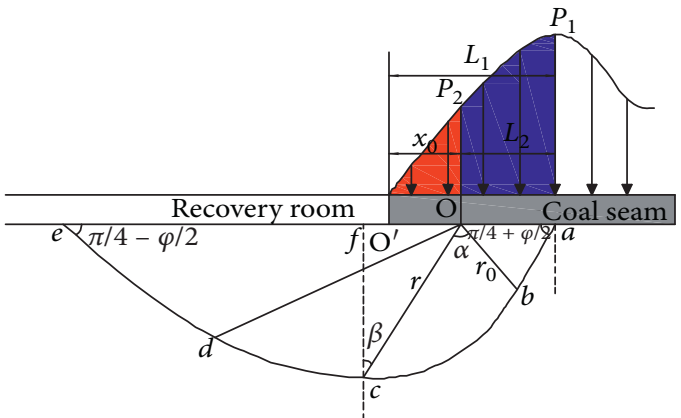

(b)

FIGURE 8: Calculation model for failure mechanics of DPRR floor.

line of the coal pillar floor should be redrawn, as shown in Figure 8.

Assume that the peak stress of the coal pillar beside the DPRR is $K \gamma H$, the distribution of the front abutment pressure between the peak stress position and the edge of the coal pillar is linear. From the geometric relationship of the fender stress distribution [37],

$$
\frac{x_{0}}{L_{1}}=\frac{P_{2}}{P_{1}},
$$

where $x_{0}$ is the width of the stress-relaxation plastic zone, m; $L_{1}$ is the distance from the maximum front abutment pressure point of the fender to the main recovery room, $\mathrm{m}$; $P_{2}$ is peak stress value of coal pillar $(K \gamma H), \mathrm{MPa} ; P_{1}$ is the weight of the overburden $(\gamma H), \mathrm{MPa} K$ is the stress-concentration factor of the fender; $\gamma$ is the unit weight of the overburden, $\mathrm{kN} / \mathrm{m}^{3}$; and $H$ is the buried depth of the coal seam, $m$.

The width of the stress-relaxation plastic zone can be calculated by equation (2), and the coal pillar width $L_{2}$ used for the calculation of the floor failure depth is obtained by the following formula:

$$
L_{2}=L_{1}-x_{0}
$$

$L_{1}$ may exert a great effect on the stability of the pillar and affects the stress distribution law in coal mass, the integrity, and external mechanical situation of DPRR. $L_{1}$ can be calculated by the following equation [25]:

$$
L_{1}=\frac{M}{2 \xi f} \ln \frac{K \gamma H+C \cot \varphi}{\xi\left(p_{1}+C \cot \varphi\right)},
$$

where $K$ is the stress-concentration factor; $p_{1}$ is the support resistance to solid coal rib; $M$ is the coal seam thickness; $H$ is the cover depth of the coal seam, $\mathrm{m}$; $C$ is the cohesion of the coal; $\varphi$ is the angle of internal friction; $f$ is the coefficient of friction between coal seam and roof and floor; $\xi=(1+\sin \varphi / 1-\sin \varphi)$.

$L_{2}$ calculated above is the corrected width of the coal pillar, and the corresponding floor slip damage zone is also adjusted accordingly. The active stress zone (I) is corrected by $\mathrm{O}^{\prime} \mathrm{ab}$ to $\mathrm{Oab}$, the transition zone (II) is adjusted from O'bcd to Obcd, and the passive stress zone (III) is adjusted from O'de to Ode, as shown in Figure 8.

\section{Theoretical Calculation of DPRR Floor Failure}

4.1. Calculation of Floor Failure Range. Based on the Prandtl solution of foundation bearing capacity and by integrating equation (1) [38], the logarithmic spiral polar coordinate equation of the fender floor slip line can be obtained:

$$
r=r_{0} \mathrm{e}^{\alpha \tan \varphi},
$$

where $r$ is the spiral radius, that is, the length of Oc, $m ; r_{0}$ is the length of $\mathrm{Ob}, \mathrm{m}$; and $\alpha$ is the angle between $r$ and $r_{0}$, as shown in Figure 8.

The depth of damage in the DPRR floor is as follows: 


$$
D=r \cos \beta,
$$

where $D$ is the damage depth of the floor, that is, the length of the broken line (cf) and $\beta$ is the angle between $r$ and cf, as shown in Figure 8.

It is easily obtained from geometric relations: $\beta=\alpha-$ $(\pi / 4)+(\varphi / 2)$ and $r_{0}=\left(L_{2} / 2 \cos (\pi / 4)+(\varphi / 2)\right)$; the limit is taken with $\left(d_{D} / d_{\alpha}\right)=0$, the value of the floor failure depth reaches the maximum, and the value of $\alpha$ can also be calculated, $\alpha=(\pi / 4)+(\varphi / 2)$. By substituting equations (2)-(5) into equation (6), the maximum failure equation for the DPRR floor can be obtained:

$$
D_{\max }=\frac{M(K-1) \cos \varphi}{4 \xi f K \cos (\pi / 4+\varphi / 2)} \ln \frac{K \gamma H+C \cot \varphi}{\xi\left(p_{1}+C \cot \varphi\right)} \mathrm{e}^{(\pi / 4)+(\varphi / 2) \tan \varphi} .
$$

The above analysis calculates the maximum damage depth of the DPRR floor. In order to further analyze the influence of the fender stress on the main recovery room, the damage width of the floor needs to be calculated. Considering that the stress concentration of the coal pillar is the main factor causing the damage of the DPRR floor, the damage width of the floor under vertical stress is mainly analyzed. The damage depth of the main recovery room floor at any point is obtained by equation (6):

$$
L_{3}=D \tan \beta \text {. }
$$

Substituting equation (7) into equation (8), the horizontal damage width corresponding to the depth of the maximum damage can be obtained:

$$
L_{3}=\frac{M(K-1) \sin \varphi}{4 \xi f K \cos (\pi / 4+\varphi / 2)} \ln \frac{K \gamma H+C \cot \varphi}{\xi\left(p_{1}+C \cot \varphi\right)} \mathrm{e}^{(\pi / 4)+(\varphi / 2) \tan \varphi} .
$$

4.2. Result Analysis. Based on the geological data of 31109 panel, the cover depth is about $H=230 \mathrm{~m}$; 3-1\# coal seam is $6.2 \mathrm{~m}$ thick; $\gamma=25 \mathrm{kN} / \mathrm{m}^{3}$; the sizes of DPRR are $5.4 \mathrm{~m}$ (width) $\times 4 \mathrm{~m}$ (height); friction coefficient between coal seam and floor is 0.1. In order to study the influence of the width of the fender, the friction angle, and the cohesion of the floor rock layer on the damage range of the DPRR floor, take the width of the fender $20 \mathrm{~m}, 30 \mathrm{~m}, 40 \mathrm{~m}$, and $50 \mathrm{~m}$, respectively; take the friction angle $(\varphi) 30^{\circ}$ to $45^{\circ}$ respectively; take cohesion $(C) 1 \mathrm{MPa}$ to $1.5 \mathrm{MPa}$, respectively. Results are shown in Figures 9 and 10.

Figure 9 shows that, with the advance of the working face, the size of the fender is reduced, the depth of floor damage is sharply increased, and the width of the floor damage is also increased. The reason is that peak front abutment pressure obviously increases in the final mining stage. The size reduction of the coal pillar also causes the peak position of the front abutment pressure to move toward the center of the fender; therefore, $L_{1}$ is also increased. The superposition of the above two factors causes the damage depth of the DPRR floor to increase significantly. Taking the size of the fender of $20 \mathrm{~m}$ as an example, the maximum

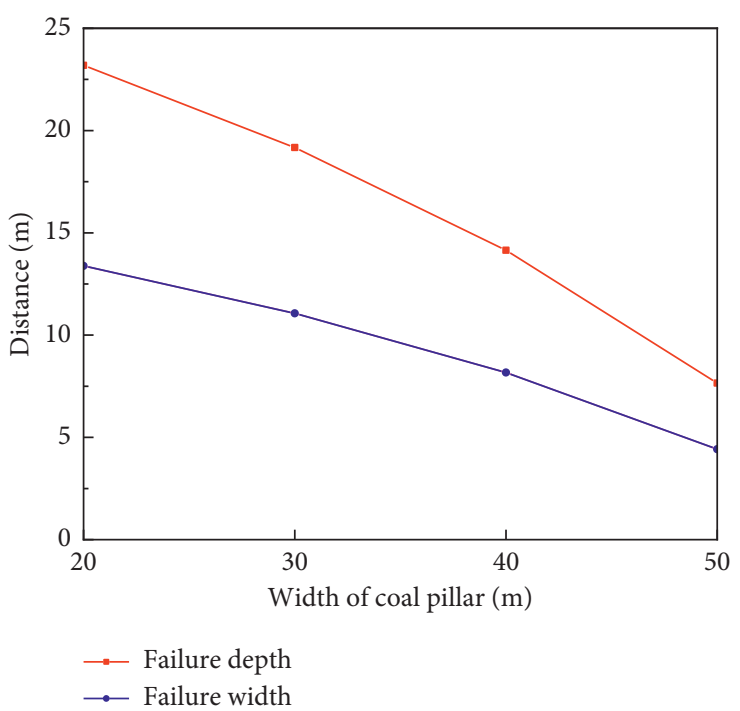

FIgURE 9: Curves of the damage range of the DPRR floor with the fender width.

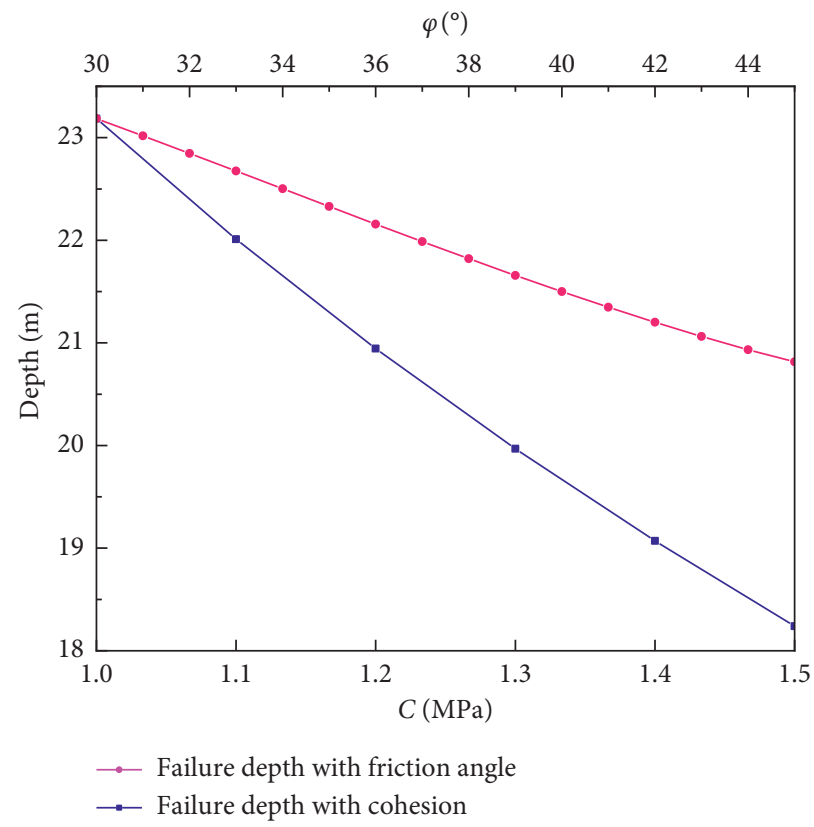

FIgURE 10: Curves of the damage depth of the DPRR floor with friction angle and cohesion.

failure depth of the DPRR floor is $23.19 \mathrm{~m}$ and the maximum failure width is $13.39 \mathrm{~m}$. It can be seen that the main predriven recovery room is within the zone of influence of the floor damage. Due to the large depth of damage of the floor, the main predriven recovery room floor will inevitably become the main place for the stress release. The floor heave is the main form of stress relief, so it is necessary to timely strengthen the support of DPRR and control floor heave in the final mining stage.

Figures 9 and 10 show that the damage depth is reduced by $21.3 \%$ and $10.2 \%$, respectively, with the increase of cohesion and friction angle of the DPRR floor. Therefore, floor 
grouting and constructing concrete used in the DPRR floor to reduce the damage range are effective and economic ways to control the floor heave.

\section{Numerical Simulation}

In order to grasp the stress distribution of the DPRR floor in the final mining stage, FLAC3D was employed to simulate the extraction of 31109 panel. The elastoplastic Mohr-Coulomb model is adopted as the failure criterion of the roof, coal, and floor strata [39]. The physical and mechanical parameters are obtained by laboratory tests on rocks which are given in Table 1 . Numerical simulation's accuracy depends on model establishment, constitutive model, mesh size, and rock mass parameters, etc. Therefore, a random mesh using Ansys is used to avoid the influence of artificial meshing on the results [40].

5.1. Model Establishment. As the inclination angle of the coal seam is very small $\left(0 \sim 3^{\circ}\right)$ which has little influence on the stress distribution of DPRR, a numerical model without taking inclination angle into account was constructed by assuming that the coal seam is completely horizontal $[21,39]$. The model dimensions are $245.8 \mathrm{~m}$ (length) $\times 70 \mathrm{~m}$ (width) $\times 72.5 \mathrm{~m}$ (height), the thickness of the coal seam is $6.2 \mathrm{~m}$, the width of DPRR is $5.4 \mathrm{~m}$, and the total excavation distance of the working face is $120 \mathrm{~m}$. A uniform stress of $157.5 \mathrm{~m} \times 0.025 \mathrm{MN} / \mathrm{m}^{3}=3.94 \mathrm{MPa}$ was applied to the top of the model corresponding to $157.5 \mathrm{~m}$ of overburden strata by assuming the overlying unit weight of $0.025 \mathrm{MN} / \mathrm{m}^{3}$. Four side surfaces of the model are fixed horizontally, and the bottom surface is fixed vertically. $45 \mathrm{~m}$ of coal is left between the model boundary and setting up room, stopping line to eliminate the boundary effect [41], as shown in Figure 11.

5.2. Simulation Results and Analysis. Figure 12 shows the vertical stress distribution around the DPRR when the interDPRR pillars are $10 \mathrm{~m}, 15 \mathrm{~m}, 20 \mathrm{~m}, 25 \mathrm{~m}$, and $30 \mathrm{~m}$ wide. The peak stress of the surrounding rock of the DPRR is about 8.1 MPa, which indicates that the change of the size of the inter-DPRR pillar has less influence on the stress distribution of the surrounding rock in the tunneling stage of the DPRR. Figure 13 shows the curves of the front abutment pressure, peak stress of the fender, and inter-DPRR pillar with the mining distance of the working face. It shows that the front abutment pressure, peak stress of the fender, and inter-DPRR pillar increase with longwall mining. The slope of the front abutment pressure growth starts to reduce when the working face advances $60-70 \mathrm{~m}$, and the peak stress of the fender is also greater than the peak stress of the interDPRR pillar when the working face advances about $65 \mathrm{~m}$.

The peak stresses of the fender and inter-DPRR pillar gradually increase after the working face advances $70 \mathrm{~m}$, especially after $80 \mathrm{~m}$, indicating that the range of the influence of the front abutment pressure is between $40 \mathrm{~m}$ and $50 \mathrm{~m}$. It can also be seen that when the inter-DPRR pillar is $10 \mathrm{~m}$, the peak front abutment pressure and the peak stresses of the fender and inter-DPRR pillar are significantly higher than those of other sizes of inter-DPRR pillars, and the peak front abutment pressure is even up to $30 \mathrm{MPa}$, which is easy to fail the surrounding rock of the DPRR, indicating that the size of the inter-DPRR pillar is unreasonable. Therefore, it is necessary to determine a reasonable and economical size of inter-DPRR pillar.

Based on the above analysis, Figures 12 and 14 demonstrate that, during the final mining stage, the stress of DPRR surrounding rock will rise sharply, especially when the inter-DPRR pillar is less than $20 \mathrm{~m}$. When the fender is reduced to $10 \mathrm{~m}$, the front abutment pressure reaches the maximum with a value of $25 \mathrm{MPa}$. After the fender is extracted, the peak stress of inter-DPRR pillar raises to $23 \mathrm{MPa}$. This shows that the DPRR has been in a high stress environment in the final mining stage. With the mining of the working face, the stress distributions of the fender and inter-DPRR pillar are similar, and the peak stresses of interDPRR pillars of different sizes are also close. It is indicated that when the size of the inter-DPRR pillar is greater than $15 \mathrm{~m}$, the effect by increasing the coal pillar size for lowering the peak surrounding rock stress of the main recovery room is limited.

The above analysis shows that the DPRR has been in a high stress environment in the final mining stage. Therefore, the stability of the fender and inter-DPRR pillars is crucial for the successful recovery of the fully mechanized mining equipment. According to the results of numerical simulation combined with the Bieniawski equation [42], the stability of the pillar in the final mining stage is analyzed. The equation is as follows:

$$
R=R_{c 1}\left(0.64+0.36 \frac{B}{h}\right)
$$

where $R$ is the strength of the coal pillar, $\mathrm{MPa} ; R_{c 1}$ is the critical dimension strength of the coal pillar, MPa; $B$ is the width of the coal pillar, $\mathrm{m}$; $h$ is the height of the coal pillar, $\mathrm{m}$.

Based on the geological data and rock mechanics experiment of 31109 panel, the following parameters are obtained: $R_{c 1 f a}=14.5 \mathrm{MPa}, \quad R_{c 1 c}=12.3 \mathrm{MPa}, h_{f}=6.2 \mathrm{~m}$, and $h_{c}=4 \mathrm{~m} . R_{c 1 f}$ is the critical dimension strength of the fender, $R_{c 1 c}$ is the critical dimension strength of the chain pillar, $h_{f}$ is the height of the fender, and $h_{c}$ is the height of the coal pillar. Substituting the above parameters into equation (10), the strengths of the fender and inter-DPRR pillar with different widths are shown in Figure 15.

It can be seen from Figure 15 that when the width of the fender is $0 \mathrm{~m}$ (Figure 14), the peak stress of the inter-DPRR pillar reaches the maximum, which corresponds to the critical width of the inter-DPRR pillar of $17.79 \mathrm{~m}$. Considering the loss of plastic deformation and preventing suddenly instability of the coal pillars in the final mining stage, the reasonable width of the inter-DPRR pillar is $20 \mathrm{~m}$. In addition, the intersection point coordinates of the widthstrength curve and width-front abutment pressure curve for the fender is $(18.48,24.84)$, indicating that, in the final mining stage, the critical width of the fender is $18.48 \mathrm{~m}$, which is also the maximum size for the fender to secondary reinforced support with the advance of the panel. 
TABle 1: Properties of strata.

\begin{tabular}{|c|c|c|c|c|c|c|c|}
\hline Lithology & Thickness (m) & $\begin{array}{c}\text { Elastic modulus } B \\
(\mathrm{GPa})\end{array}$ & $\begin{array}{c}\text { Shear modulus } S \\
(\mathrm{GPa})\end{array}$ & $\begin{array}{c}\text { Compressive strength } \sigma \\
(\mathrm{MPa})\end{array}$ & $\begin{array}{c}\text { Cohesion } C \\
(\mathrm{MPa})\end{array}$ & $\begin{array}{l}\text { Friction } \\
\text { angle }\left({ }^{\circ}\right)\end{array}$ & $\begin{array}{l}\text { Density } \rho \\
\left(\mathrm{Kg} / \mathrm{m}^{3}\right)\end{array}$ \\
\hline $\begin{array}{l}\text { Sandy } \\
\text { mudstone }\end{array}$ & 4.9 & 13.0 & 8.5 & 9.63 & 2.51 & 34.9 & 2550 \\
\hline Siltstone & 4.0 & 19.0 & 14.8 & 27.00 & 6.01 & 41.9 & 2540 \\
\hline Siltstone & 5.5 & 19.0 & 14.8 & 27.00 & 6.01 & 41.9 & 2540 \\
\hline Fine sandstone & 18.6 & 18.7 & 15.2 & 28.40 & 6.25 & 42.5 & 2550 \\
\hline $\begin{array}{l}\text { Sandy } \\
\text { mudstone }\end{array}$ & 6.4 & 13.0 & 8.5 & 9.63 & 2.51 & 34.9 & 2550 \\
\hline 3-1\# coal seam & 6.2 & 11.9 & 7.1 & 4.59 & 1.35 & 29.2 & 1400 \\
\hline Mudstone & 12.8 & 12.4 & 8.1 & 9.41 & 2.62 & 31.7 & 2550 \\
\hline Siltstone & 9.2 & 19.0 & 14.8 & 27.00 & 6.01 & 41.9 & 2540 \\
\hline $\begin{array}{l}\text { Sandy } \\
\text { mudstone }\end{array}$ & 4.9 & 13.0 & 8.5 & 9.63 & 2.51 & 34.9 & 2550 \\
\hline
\end{tabular}

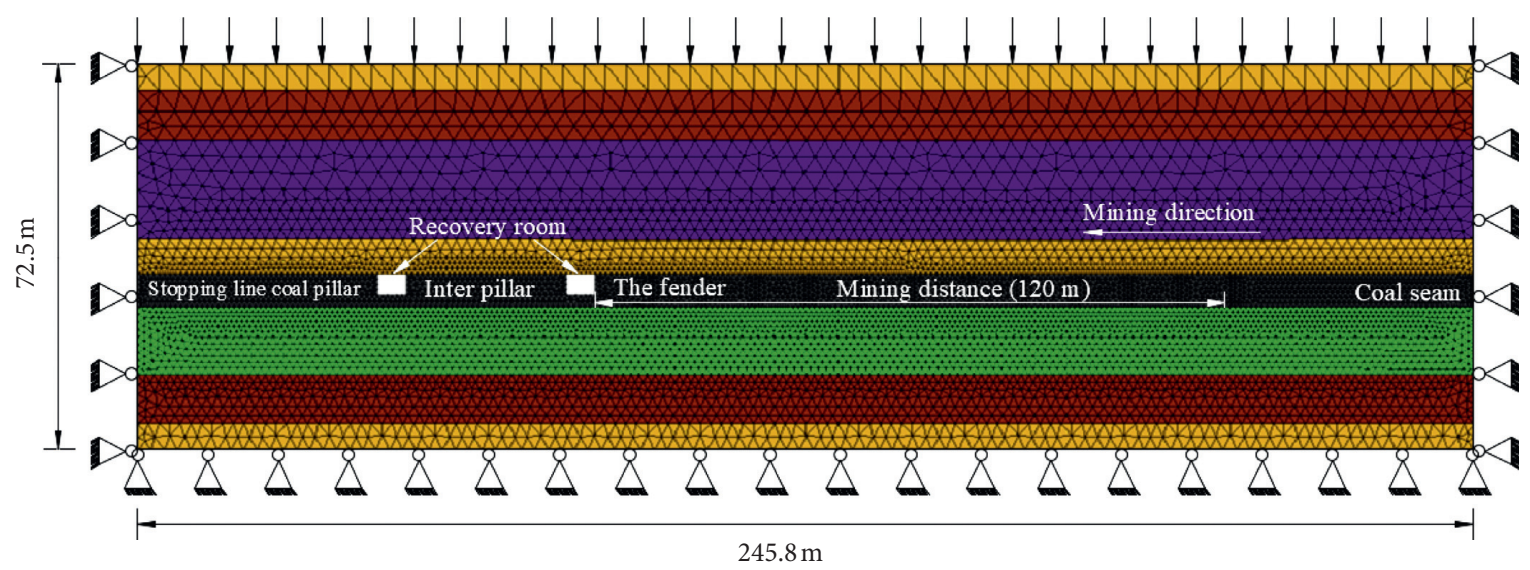

FIgURE 11: FLAC3D model.

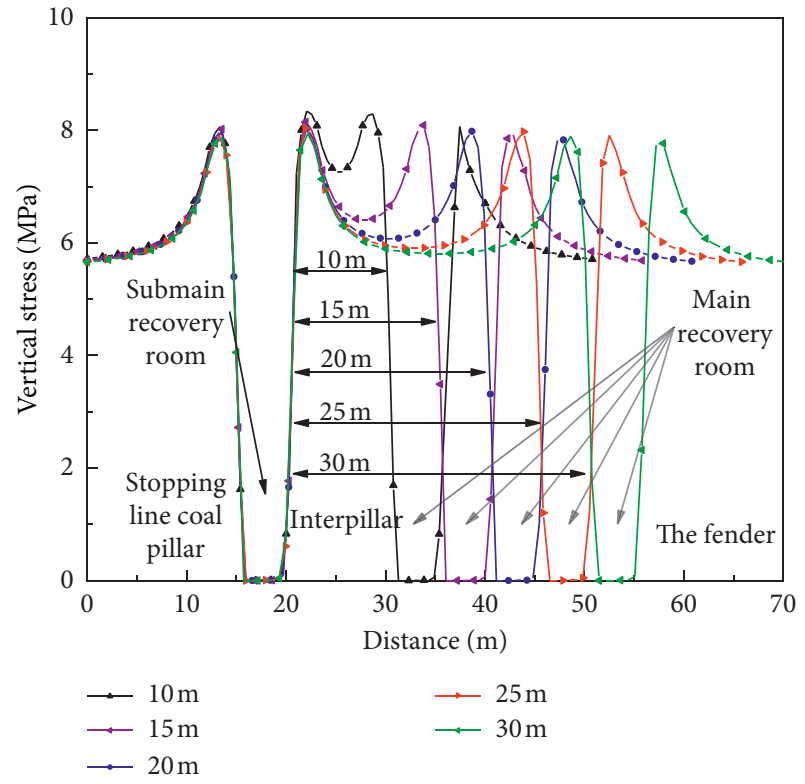

FIGURE 12: Vertical stress distribution of the fender with different sizes at the DPRR excavation stage.

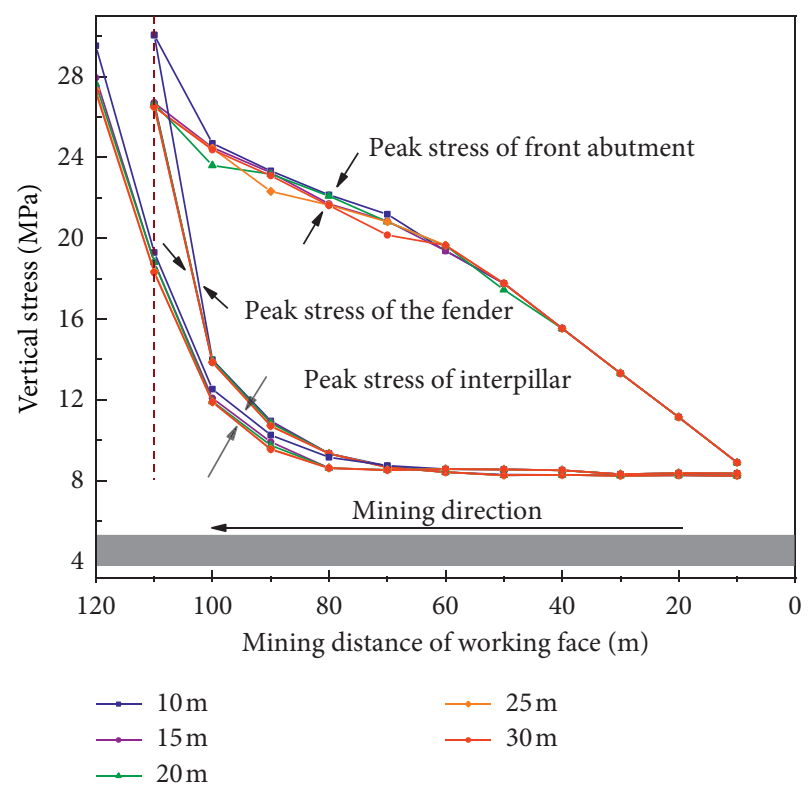

FIGURE 13: Curves of peak stress of front abutment, the fender, and inter-DPRR pillar with longwall mining. 


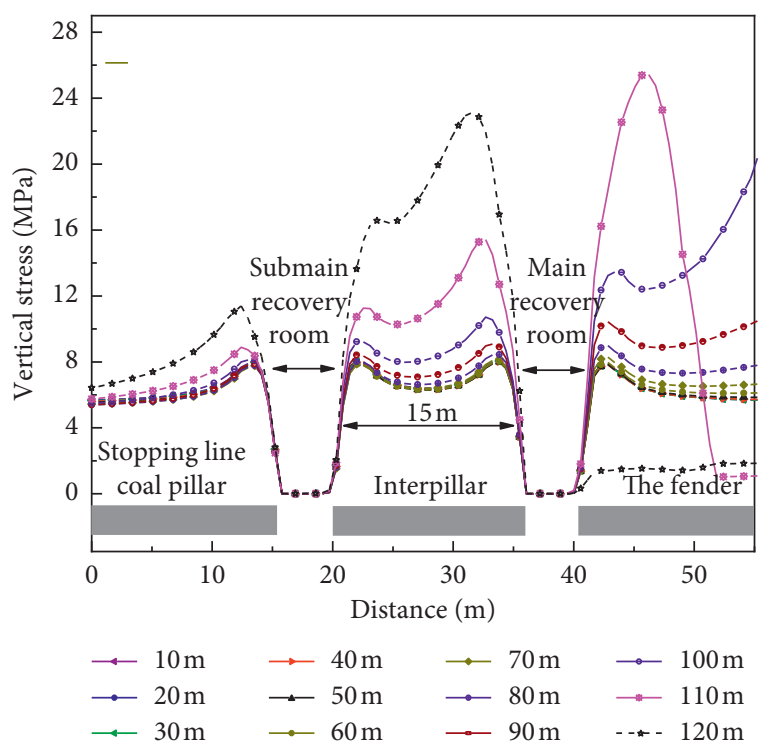

(a)

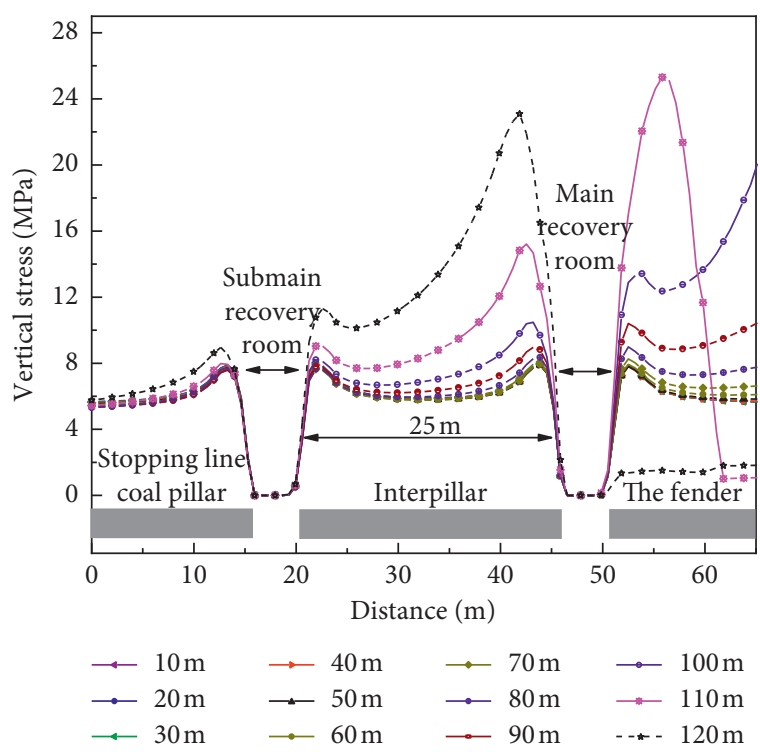

(c)

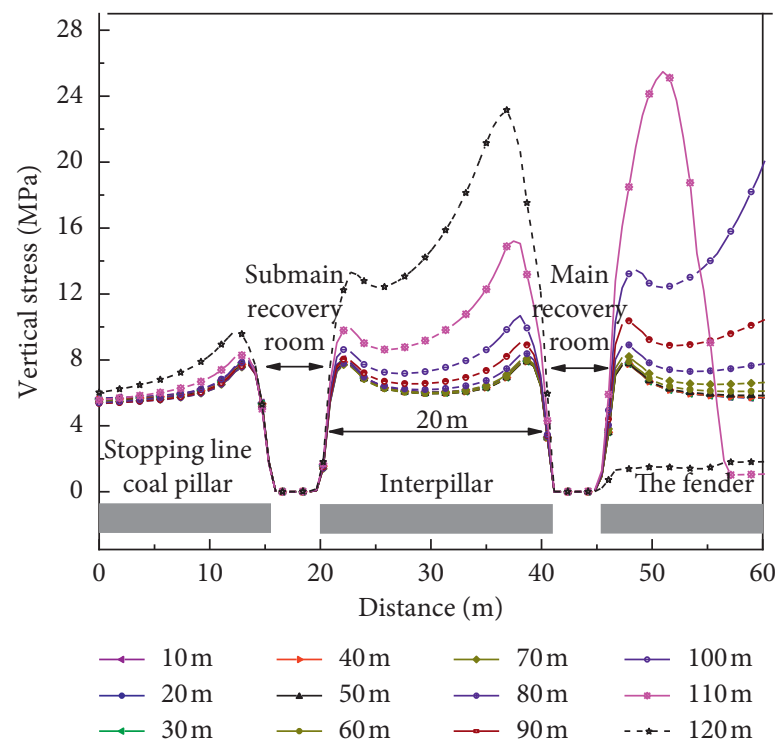

(b)

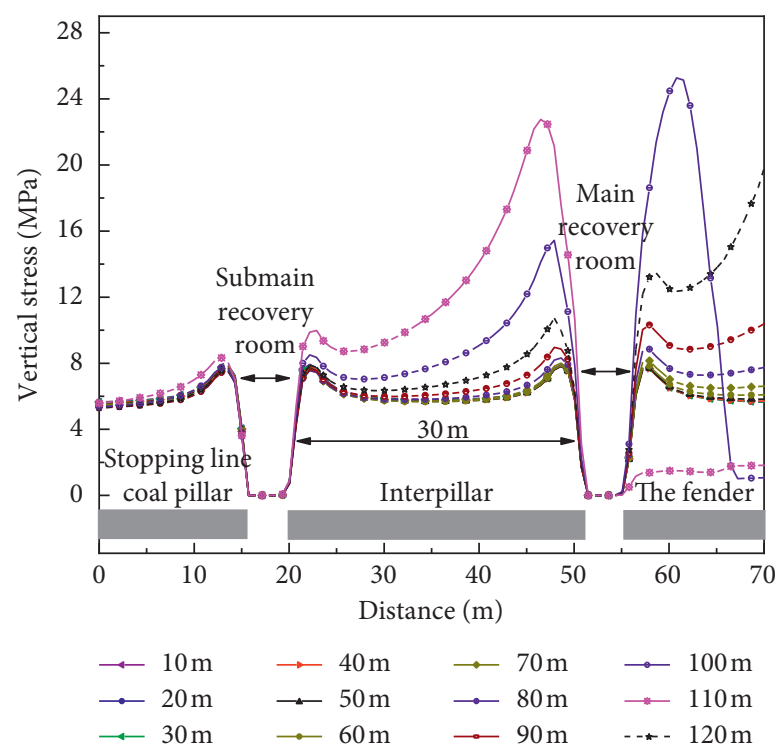

(d)

FIGURE 14: Distribution curves of vertical stress around the DPRR with different sizes of inter-DPRR pillar: (a) $15 \mathrm{~m}$, (b) $20 \mathrm{~m}$, (c) $25 \mathrm{~m}$, and (d) $30 \mathrm{~m}$ as the longwall mining.

The above results show that the reasonable size of the inter-DPRR pillar is $20 \mathrm{~m}$; combined with Figure 14(b), the DPRR is in a high stress environment in the final mining stage. Therefore, the distribution of floor heave of DPRR is shown in Figure 16.

It can be observed from Figure 16(a) that the value of floor heave tends to increase at first and then decrease with depth and reaches the maximum in the depth of $5 \mathrm{~m}$, indicating that $5 \mathrm{~m}$ is the starting point for the initial depth of the floor heave. This can be a piece of advice for floor heave prevention. Figure 16(b) shows that the value of floor heave increased significantly after the width of the fender is less than $50 \mathrm{~m}$. As the working face advances, the value of floor heave is consistently changing with surrounding rock stress distribution of DPRR; therefore, the value of floor can be controlled by reducing the surrounding rock stress in the final mining stage.

Numerical simulation and theoretical calculations show that the timely secondary support and grout reinforcing technology in DPRR floor can avoid the dynamic disaster of coal pillars and relieve the degree of floor heave.

\section{Conclusions and Suggestions}

Based on geological conditions, theoretical analysis and numerical simulation were performed to study the distribution of front abutment pressure and the failure range of 


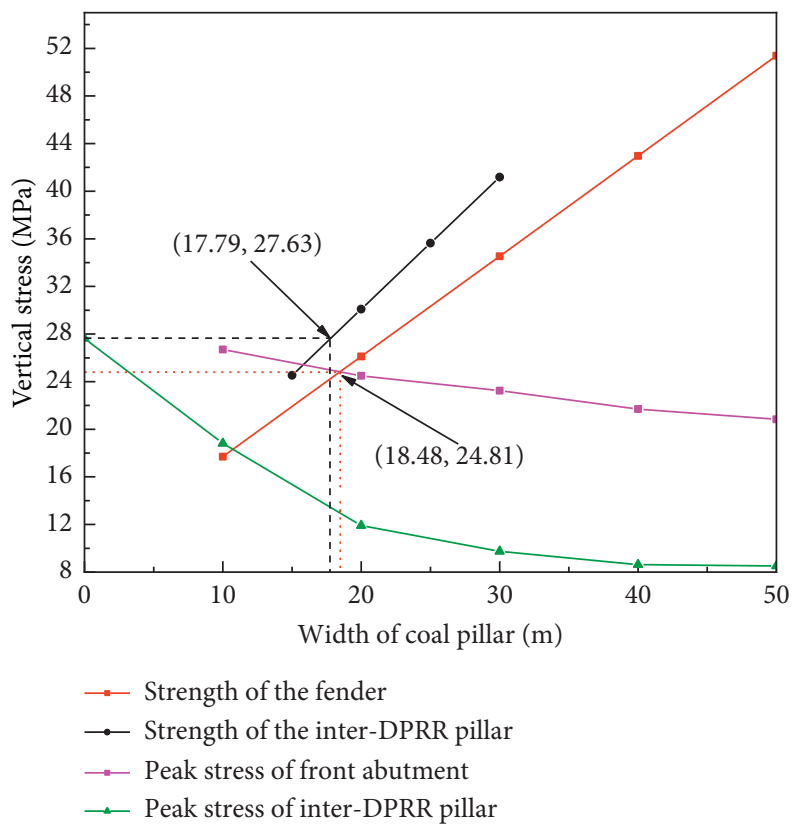

FIGURE 15: Comparison of bearing capacities and peak stresses of the coal pillars with different widths.

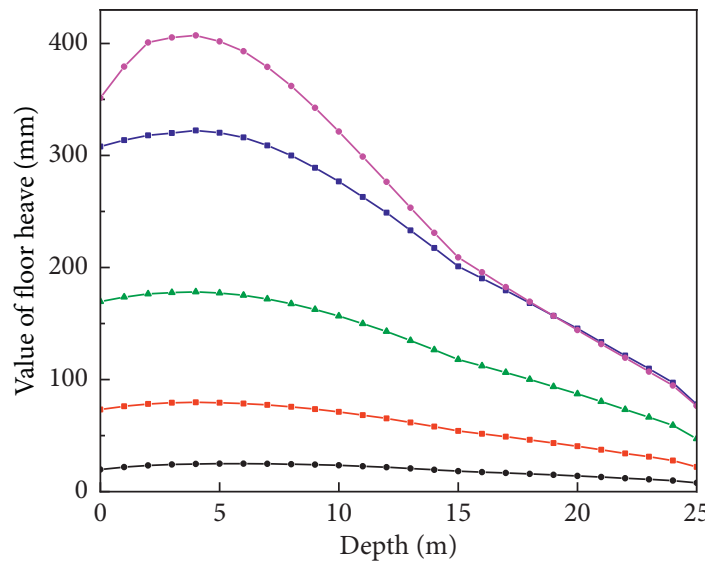

Mining distance of working face:

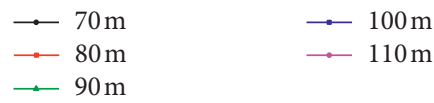

(a)

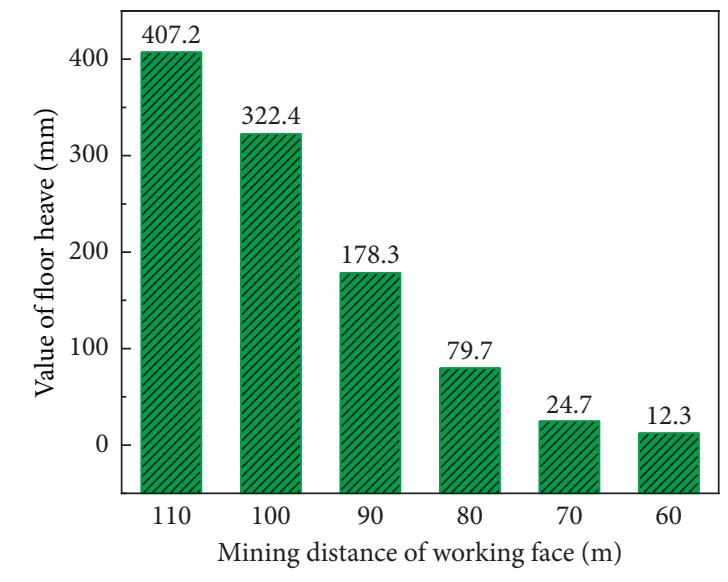

(b)

FIGURE 16: Distribution of DPRR floor heave when the inter-pillar is $20 \mathrm{~m}$. (a) Distribution of floor heave with longwall mining. (b) Maximum value of floor heave with longwall mining.

the DPRR floor in the final mining stage. The following conclusions are obtained:

(1) The fender stress distribution can be approximately divided into three stages: stress redistribution (the first) stage, stress superimposed growth (the second) stage, and stress transfer (the third) stage.

(2) According to stress distribution and corresponding failure mode of the fender, the calculation model of the slippage damage of the DPRR floor is rectified, and the damage range of the floor is rezoned to make it more suitable for the damage depth of the room.

(3) Numerical simulation shows that the zone of influence of the front abutment pressure is $40-50 \mathrm{~m}$, and the surrounding stress of the DPRR will increase significantly in the final mining stage. When the size of the inter-DPRR pillar is greater than $15 \mathrm{~m}$, the effect of increasing the coal pillar size on lowering the peak surrounding rock stress of the main recovery room is limited. The value of floor heave tends to 
increase at first and then decrease with depth and reaches the maximum in the depth of $5 \mathrm{~m}$ in the final mining stage, and the evolution of floor heave is consistent with that of surrounding rock stress distribution of DPRR.

(4) The theoretical calculation shows that inter-DPRR pillar of $20 \mathrm{~m}$ is more reasonable. The critical width of the fender is $18.48 \mathrm{~m}$, which is also the maximum size for the fender to strengthen and support with the advance of the working face. Floor grouting and constructing concrete used in the DPRR floor to reduce the damage range are effective and economic ways to control the floor heave.

\section{Data Availability}

The data used to support the findings of this study are included within the article.

\section{Conflicts of Interest}

The authors declare that they have no conflicts of interest.

\section{References}

[1] T. M. Barczak, S. C. Tadolini, and P. Y. Zhang, "Evaluation of support and ground response as longwall face advances into and widens pre-driven recovery room," 1900.

[2] S. Tadolini and T. Barczak, "Design parameters of roof support systems for pre-driven longwall recovery rooms," 1900.

[3] D. Wichlacz, T. Britten, and B. Beamish, "Development of pre-driven recovery evaluation program for longwall operations," 2009.

[4] W. Zhu, D. Ren, and M. Chen, "Rational buried depth for regulating roadway application duringcoal face withdrawal in Shendong mining area," Journal of Mining \& Safety Engineering, vol. 32, no. 2, pp. 279-284, 2015.

[5] D. Oyler, R. Frith, D. Dolinar, and C. Mark, "International experience with longwall mining into pre-driven rooms," 1900.

[6] T. Wynne, S. John, S. Guo, and S. S. Peng, Eds., in Proceedings of 12th International Conference on Ground Control in Mining, Morgantown, WV, USA, 1993.

[7] S. C. Tadolini, "Ground control support consideration for predriven longwall recovery rooms," 2004.

[8] L. Jiang, Q. Wu, Q. Wu et al., "Fracture failure analysis of hard and thick key layer and its dynamic response characteristics," Engineering Failure Analysis, vol. 98, pp. 118-130, 2019.

[9] Y. Chen, J. Bai, S. Yan, Y. Xu, X. Wang, and S. Ma, "Control mechanism and technique of floor heave with reinforcing solid coal side and floor corner in gob-side coal entry retaining," International Journal of Mining Science and Technology, vol. 22, no. 6, pp. 841-845, 2012.

[10] Q. Zhang, C.-H. Peng, R.-C. Liu, B.-S. Jiang, and M.-M. Lu, "Analytical solutions for the mechanical behaviors of a hard roof subjected to any form of front abutment pressures," Tunnelling and Underground Space Technology, vol. 85, pp. 128-139, 2019.

[11] C. Liu, P. Gong, K. Wang, X. Zhang, and Y. Liu, "Roof stability for repeated mining workface passing through abandoned parallel gateway," Journal of China Coal Society, vol. 40, no. 2, pp. 314-322, 2015.

[12] C. Yin, G. Feng, P. Gao, and P. Zhao, "Research on instability mechanism of surrounding rock in stage of working face passing abandoned roadway," Journal of Mining \& Safety Engineering, vol. 35, no. 03, pp. 457-464, 2018.

[13] C. Liu, Z. Yang, P. Gong et al., "Accident analysis in relation to main roof structure when longwall face advances toward a roadway: a case study," Advances in Civil Engineering, vol. 2018, 2018.

[14] X. Wang, J. Xu, W. Zhu, and J. Ju, "Influence of high mining velocity on periodic weighting during fully-mechanized mining in a shallow seam," Journal of China University of Mining \& Technology, vol. 41, no. 3, pp. 349-354, 2012.

[15] B. Wang, F. Dang, W. Chao, Y. Miao, J. Li, and F. Chen, "Surrounding rock deformation and stress evolution in predriven longwall recovery rooms at the end of mining stage," International Journal of Coal Science \& Technology, vol. 6, no. 4, pp. 536-546, 2019.

[16] S. Xie, S. Li, and Z. Wei, "Stability control of support surrounding rock system during fully mechanized caving face crossing abandoned roadway period," Journal of China Coal Society, vol. 40, no. 3, pp. 502-508, 2015.

[17] S. Gu, R. Huang, J. Li, and P. Su, "Stability analysis of unmined coal pillars during the pressure adjustment prior to working face transfixion," Journal of Mining \& Safety Engineering, vol. 9, no. 1, 2017.

[18] C. Liu, J. Zhang, Z Yang et al., "Mechanism of advance fracture of main roof and its control technology when workface crossing abandoned roadway," Rock and Soil Mechanics, vol. 39, no. 4, pp. 1411-1421, 2018.

[19] X. Yu, Q. Wang, and B. Zhao, "Study on reasonable width of pillar between roadways in large mining height face with double roadways layout," Chinese Journal of Rock Mechanics and Engineering, vol. 34, no. S1, pp. 3328-3336, 2015.

[20] S. Zhu, Y. Feng, and F. Jiang, "Determination of abutment pressure in coal mines with extremely thick alluvium stratum: a typical kind of rockburst mines in China," Rock Mechanics and Rock Engineering, vol. 49, no. 5, pp. 1943-1952, 2016.

[21] Z. Mu, G. Liu, J. Yang et al., "Theoretical and numerical investigations of floor dynamic rupture: a case study in Zhaolou Coal Mine, China," Safety Science, vol. 114, pp. 1-11, 2019.

[22] S. B. Tang and C. A. Tang, "Numerical studies on tunnel floor heave in swelling ground under humid conditions," International Journal of Rock Mechanics and Mining Sciences, vol. 55, pp. 139-150, 2012.

[23] W. Zhu, J. Xu, and G. Xu, "Mechanism and control of roof fall and support failure incidents occurring near longwall recovery roadways," Journal of the Southern African Institute of Mining and Metallurgy, vol. 117, no. 11, pp. 1063-1072, 2017.

[24] S. Gu, B. Huang, R. Huang, and Y. Miao, "Method for determining the load on and width of coal pillar at the recovery room end of fully-mechanized longwall mining," Journal of China University of Mining \& Technology, vol. 44, no. 6, pp. 990-995, 2015.

[25] Y. Li, M. Lei, H. Wang et al., "Abutment pressure distribution for longwall face mining through abandoned roadways," International Journal of Mining Science and Technology, vol. 9, no. 1, 2019.

[26] Q. Wang, Y. Fan, G. Li, W. Guo, D. Yan, and L. Zhang, "Determination of coal pillar width between roadways of fully mechanised caving face with double roadways layout in a 
thick coal seam," Rock and Soil Mechanics, vol. 38, no. 10, pp. 3009-3016, 2017.

[27] H. Jia, L. Wang, S. Liu et al., "Mechanism and control strategy of asymmetrical floor heave of coal pillar roadway in fully mechanized caving face," Journal of China Coal Society, vol. 44, no. 4, pp. 1030-1040, 2019.

[28] F. Zhang, B. Shen, and Y. Kang, "Failure mechanism of coal seam floor and calculation of maximum breaks depth," Process of Safety Environmental Project, vol. 42, pp. 58-61, 2015.

[29] X. Zhang, "Prandtl and terzaghi bearing capacity formulas of a strip footing solved by slip-line method of plasticity," Journal of Tianjin University, vol. 2, 1987.

[30] B. H. Brady and E. T. Brown, Rock Mechanics: For Underground Mining, Springer Science \& Business Media, Berlin, Germany, 2013.

[31] P. Tapponnier and P. Molnar, "Slip-line field theory and largescale continental tectonics," Nature, vol. 264, no. 5584, pp. 319-324, 1976.

[32] D. F. McCarthy, Essentials of Soil Mechanics and Foundations, Reston Publishing Company Virginia, New York,NY, USA, 1977.

[33] B. Meng, H. Jing, K. Chen, and H. Su, "Failure mechanism and stability control of a large section of very soft roadway surrounding rock shear slip," International Journal of Mining Science and Technology, vol. 23, no. 1, pp. 127-134, 2013.

[34] A. Iannacchione, "The effects of roof and floor interface slip on coal pillar behavior," 1900.

[35] C. Wang, A. Cao, G. Zhu, G. Jing, J. Li, and T. Chen, "Mechanism of rock burst induced by fault slip in an island coal panel and hazard assessment using seismic tomography: a case study from Xuzhuang colliery, Xuzhou, China," Geosciences Journal, vol. 21, no. 3, pp. 469-481, 2017.

[36] D. C. Drucker and W. Prager, "Soil mechanics and plastic analysis or limit design," Quarterly of Applied Mathematics, vol. 10, no. 2, pp. 157-165, 1952.

[37] B. A. Poulsen, "Coal pillar load calculation by pressure arch theory and near field extraction ratio," International Journal of Rock Mechanics and Mining Sciences, vol. 47, no. 7, pp. 1158-1165, 2010.

[38] D. V. Griffiths and G. A. Fenton, "Bearing capacity of spatially random soil: the undrained clay Prandtl problem revisited," Géotechnique, vol. 51, no. 4, pp. 351-359, 2001.

[39] G. Feng, P. Wang, and Y. P. Chugh, "Stability of gate roads next to an irregular yield pillar: a case study," Rock Mechanics and Rock Engineering, vol. 52, no. 8, pp. 2741-2760, 2018.

[40] Q. Liao, Q. Zeng, T. Liu, S. Lu, and Z. Hou, "Automatic modelgeneration of complex geologic body with FLAC3D based on ANSYS platform," Chinese Journal of Rock Mechanics and Engineering, vol. 6, 2005.

[41] A. Jaiswal and B. K. Shrivastva, "Numerical simulation of coal pillar strength," International Journal of Rock Mechanics and Mining Sciences, vol. 46, no. 4, pp. 779-788, 2009.

[42] Z. T. Bieniawski, Engineering Rock Mass Classifications: A Complete Manual for Engineers and Geologists in Mining, Civil, and Petroleum Engineering, John Wiley \& Sons, Hoboken, NJ, USA, 1989. 